\title{
Right Posterolateral Basal Peripheral Zone of Prostate
}

National Cancer Institute

\section{Source}

National Cancer Institute. Right Posterolateral Basal Peripheral Zone of Prostate. NCI

Thesaurus. Code C128595.

The region of the prostate that is located on the anatomical right side of the posterolateral portion of the basal division of the peripheral zone. 